\title{
Comportamento da uva 'Malvasia Bianca' (Vitis vinifera L.) cultivada em zona subtropical
}

\section{Production Performance of 'Malvaisa Bianca' grape (Vitis vinifera $\mathbf{L}$.) grown in Subtropical Regions}

\author{
Bruno da Silva Jubileu'; Sergio Ruffo Roberto ${ }^{2 *}$; \\ Alessandro Jéferson Sato ${ }^{3}$; Cristiano Ezequiel dos Santos ${ }^{4}$
}

Resumo

O presente trabalho teve como objetivo avaliar o comportamento fenológico e produtivo da uva 'Malvasia Bianca' destinada à elaboração de vinhos brancos aromáticos no norte do Paraná. O experimento foi realizado em um vinhedo localizado em Maringá, PR, conduzido em latada em espaçamento de 4,0 x 1,5 m enxertada sobre o IAC 766 Campinas. Foram utilizadas 20 plantas previamente marcadas durante 2 safras consecutivas (2004/2005 e 2005/2006). A fenologia das videiras foi avaliada quanto à duração em dias de suas principais fases. As características químicas do mosto das bagas foram avaliadas por meio de análise semanal do $\mathrm{pH}$, teor de sólidos solúveis totais (SST), acidez titulável (AT) e relação SST/AT, a partir do início da maturação até 7 dias após a colheita. As características da produção foram avaliadas quanto ao diâmetro médio e massa média das bagas, número médio de cachos por planta, massa média dos cachos e estimativas da produção por planta e produtividade. A duração do ciclo (poda à colheita) na região foi em média 127 dias. Por ocasião da colheita, as médias do pH, teor de SST, AT e relação SST/ AT do mosto das bagas foram de 3,6;21,2 ${ }^{\circ}$ Brix; $0,6 \%$ de ácido tartárico e 36,0, respectivamente. As bagas apresentaram em média $15,5 \mathrm{~mm}$ e 2,2g. Observou-se em média 62 cachos por planta, com massa de $0,3 \mathrm{~kg}$; produção de 20,0 kg/planta e produtividade de 33,3 t/ha. Pelos resultados obtidos, verifica-se que a uva 'Malvasia Bianca' apresenta um promissor potencial de cultivo para a elaboração de vinhos brancos aromáticos no norte do Paraná.

Palavras-chave: Fenologia, vinho, viticultura

\begin{abstract}
The objective of this study was to assess the phenotypic/phenology and production performance of 'Malvasiva Bianca' grape used to make white wine at North of Parana State. The experiment was done in one vineyard located in Maringa, PR, conducted pergola system accounting with an space of 4.0 X $1.5 \mathrm{~m}$ enxert about IAC 766 Campinas. Twenty plants were used previously identified and market during two consecutive harvest seasons (2004/2005 and 2005/2006). The phenotipic performance of grape vives was assessed considering duration of time in days of their principal phases. The chemical characteristics of the berries were assessed performing weekly analysis of $\mathrm{pH}$ measurements, Total Solutable Solid (TSS), titratable Acidity (AT) and relationship TSS/TA, starting at the biggining of the maturing process
\end{abstract}

1 Mestrando em Agronomia - Universidade Estadual de Londrina-UEL, Bolsista CNPq. E-mail: brunojubileu@yahoo.com.br

2 Prof. Dr., AGRONOMIA/UEL, CP 6001, 86051-990. E-mail: sroberto@uel.br

3 Doutorando em Agronomia - Universidade Estadual de Londrina-UEL, E-mail: ajsato82@ yahoo.com.br

4 Mestre em Agronomia, E-mail: cristiano e@ @ yahoo.com.br

* Autor para correspondência 
until seven days after harvesting. The production characteristics were assessed considering the average diameter and average mass weight of the berry, number on average of clusters per plant, average mass weight of the cluster and estimates of production and productivity on each plant. The duration of production's cicle (cutting to harvest) in this region was on average 127 days. Due the harvest period, the $\mathrm{pH}$ 's average, SST, AT levels and the relationship SST/AT of the berries ranged were $3.6 ; 21.2^{\circ}$ Brix; $0.6 \%$ of Tartaric Acid and 36.0 respectively. The berry presented on average $15.5 \mathrm{~mm}$ and $2.2 \mathrm{~g}$. It was observed on average 62 clusters per plant, with mass weight of $0.3 \mathrm{Kg}$; production of $20.0 \mathrm{Kg}$ per plant and productivity of $33.3 \mathrm{t} / \mathrm{ha}$. The results showed that the 'Malvasia Bianca' grape presents a great potential to be cultivated for further make aromatic white wine at North of Parana State.

Key words: Phenology, wine, viticulture

\section{Introdução}

A viticultura no Paraná é dividida em três regiões distintas: Norte, nas cidades próximas de Maringá com alta tecnificação, predominando uvas finas de mesa; Centro-Leste, próximo à cidade de Curitiba e o Sul próximo à divisa com Santa Catarina onde predominam uvas comuns de mesa como também para processamento em áreas pouco tecnificadas, em muitos aspectos decadentes por causa da infestação maciça dos parreirais com Eurhizococcus brasiliensis, a pérola-da-terra, que vem reduzindo a produtividade como também aniquilando os parreirais (SOUSA, 1996).

Na região norte do Paraná, caracterizada pelo clima subtropical, predominam as pequenas propriedades com uso de mão-de-obra familiar, freqüentemente complementada através de contratos de parceria, remunerados com parte da produção (MELLO, 2004). Tradicionalmente são produzidas uvas finas de mesa como 'Itália', 'Rubi' (Vitis vinifera L.) para consumo como fruta fresca em duas safras anuais e também um pouco de uvas comuns com predominância da uva Niagara Rosada (Vitis labrusca $x$ Vitis vinifera L.).

Entretanto, por ocasião do aumento do volume da produção em algumas safras, tem sido observado excesso de oferta do produto no mercado acarretando uma baixa remuneração da cultura. Por esta razão, observa-se recentemente na região outro nicho de exploração para o cultivo de uvas, como o processamento tanto para elaboração de sucos como para produção de vinhos, agregando assim valor ao produto, gerando empregos no campo e também no setor industrial e comercial.
Desta forma, o cultivo de videiras destinadas à vinificação é uma alternativa para a verticalização da produção de uvas na região norte do Paraná, diversificando o atual sistema baseado na produção de uvas de mesa. Entre as uvas brancas mais cultivadas no país para vinificação e objeto de estudo deste trabalho, destaca-se a 'Malvasia Bianca' por sua produtividade e adaptação às varias regiões do mundo, originando vinhos brancos aromáticos de qualidade. Entretanto, para a determinação da adaptação de novas variedades de videiras em regiões onde o seu cultivo não é conhecido, um dos mais importantes aspectos a ser considerado é o estudo das características do potencial produtivo dessas plantas (JIMENEZ \& RUIZ, 1995).

Considerando esses aspectos, este trabalho teve como objetivo avaliar o comportamento fenológico e produtivo da videira 'Malvasia Bianca' (Vitis vinifera L.) para elaboração de vinhos finos aromáticos na região norte do Paraná.

\section{Material e Métodos}

O trabalho foi conduzido em um vinhedo comercial de uva 'Malvasia Bianca' (Vitis vinifera L.) pertencente à Vinícola Intervin ${ }^{\circledR}$, localizado no município de Maringá, PR. Os indicadores climáticos médios da região são $1.600 \mathrm{~mm}$ de precipitação anual, temperatura $20,7^{\circ} \mathrm{C}$ e $73 \%$ de umidade relativa, caracterizado assim como região subtropical onde a temperatura média dos meses mais frios (junho/julho) situa-se em torno de $16,7^{\circ} \mathrm{C}$ (BORROZINO, 2004).

A duração dos diferentes estágios fenológicos bem como as características produtivas da videira 
'Malvasia Bianca' foram estudadas durante duas safras consecutivas (2004/2005 e 2005/2006). Foram utilizadas 20 plantas uniformes previamente marcadas (Rizzon e Miele, 2004), conduzidas em latada em espaçamento de 4,0 x 1,5 m, e enxertadas em julho de 2001 sobre o porta-enxerto IAC 766 Campinas.

Para a realização da poda de frutificação, esperou-se pelo início do inchamento das gemas ocorrido no início do mês de setembro, e em seguida, foi aplicado o regulador cianamida hidrogenada a 2,5\% para a quebra da dormência das gemas da videira, com o objetivo de se obter brotação uniforme das mesmas. A poda de produção foi realizada deixando-se 4 ou 5 gemas por esporão.

Para a avaliação do comportamento fenológico das videiras, foram etiquetados 2 ramos de cada planta marcada. Foi avaliada nestes ramos, por meio de observações visuais, a duração em dias dos seguintes estádios a partir da poda de frutificação, segundo a seguinte classificação baseada em Baggiolini (1952) e Baillod e Baggiolini (1993):

a) Gema-algodão: quando $50 \%$ das gemas atingiram o segundo estádio de desenvolvimento da videira, ou seja, quando as escamas se romperam e apareceu a plumagem.

b) Brotação: quando $50 \%$ das gemas atingiram o quarto estádio, ou seja, a saída das folhas.

c) Aparecimento da inflorescência: quando $50 \%$ dos ramos apresentaram inflorescência, onde os cachos eram visíveis, embora rudimentares.

d) Florescimento: quando 50\% das flores se encontraram abertas (florescimento propriamente dito com flores visíveis).

e) Início da maturação das bagas: quando 50\% das bagas mudaram de coloração, isto é, as bagas com coloração verde amarelecido e o momento que estas iniciaram o amolecimento.

f) Colheita: momento em que $100 \%$ das bagas apresentaram coloração verde amarelado intensa, com teor máximo de sólidos solúveis totais.
Foi caracterizada então a duração em dias de cada um dos seguintes subperíodos: poda à gema-algodão; poda à brotação; poda ao aparecimento da inflorescência; poda ao florescimento; poda ao início da maturação das bagas e; poda à colheita (BOLIANI, 1994; GUERREIRO, 1997). A partir destes dados foram construídos diagramas, representando em escala, a duração em dias de cada uma das fases fenológicas da videira 'Malvasia Bianca', bem como a duração de cada subperíodo.

As características químicas das bagas, como, $\mathrm{pH}$, teor de sólidos solúveis totais (SST), expresso em ${ }^{\circ}$ Brix, acidez titulável (AT), expressa em \% de ácido tartárico e índice de maturação (SST/AT), foram avaliadas semanalmente a partir do início da maturação dos cachos até 7 dias após a colheita, por meio da coleta de 300 bagas aleatórias, subdivididas em 10 sub-amostras de 30 bagas por métodos físicoquímicos (INSTITUTO ADOLFO LUTZ, 1985). As amostras foram trituradas para a retirada do mosto, que em seguida foi filtrado com algodão para se determinar o teor de SST em refratômetro digital de bancada com compensação automática de temperatura (Krüss Optronic, modelo DR 301-95, Alemanha). A determinação da AT foi realizada por titulação do mosto com solução padronizada de $\mathrm{NaOH} 0,1 \mathrm{~N}$ em titulador potenciométrico digital (Schott Geräte, Modelo Tritoline Easy, Alemanha), com ponto final de titulação ajustado para $\mathrm{pH}=8,2$.

A partir destes dados, obteve-se, através de análise de regressão o comportamento das variáveis analisadas (pH, SST, AT e SST/AT das bagas) em função do tempo (BOLIANI, 1994; ROBERTO et al., 2002a,b) nas duas safras de avaliação.

Por ocasião da colheita foi determinado o número médio de cachos por planta. Para se determinar as características físicas dos frutos, foram coletados 5 cachos por parcela avaliando-se a sua massa $(\mathrm{kg})$. Em função do número médio de cachos por planta, da massa média dos cachos e do número de plantas por hectare, foram estimadas a produção por planta $(\mathrm{kg} / \mathrm{planta})$ e a produtividade (t/ha). Para a 
determinação do diâmetro das bagas foi utilizado um paquímetro digital (Starrett, Modelo 727-6/650, Alemanha) e a massa das bagas foi determinada pela pesagem de 30 bagas em balança semi-análitica.

\section{Resultados e Discussão}

\section{Fenologia}

O ciclo compreendido da poda à colheita para a uva 'Malvasia Bianca' em Maringá foi de 129 dias no primeiro ano de produção e a duração dos subperíodos poda à gema-algodão, poda à brotação, poda ao aparecimento da inflorescência, poda ao florescimento, poda ao início da maturação e poda à colheita foi de $11 ; 13 ; 17 ; 35 ; 86 ; 129$ dias, respectivamente (Figura 1A) com temperatura média de $23,1^{\circ} \mathrm{C}$.

No segundo ano de produção, o ciclo foi semelhante, porém um pouco mais curto, totalizando 125 dias, sendo que a duração dos subperíodos poda à gema-algodão, poda à brotação, poda ao aparecimento da inflorescência, poda ao florescimento, poda ao início da maturação e poda à colheita foi de $2 ; 17 ; 24 ; 27 ; 73 ; 125$ dias, respectivamente (Figura 1B) com temperatura média de $23,4^{\circ} \mathrm{C}$.

No Brasil, a maior área de cultivo da uva 'Malvasia Bianca' está centralizada na Serra Gaúcha, onde, segundo Giovannini (1999) esta videira apresenta ciclo da brotação até a colheita de 177 dias com temperatura média de $18,3^{\circ} \mathrm{C}$. Para as condições da província de Bari no sul da Itália o ciclo desta videira é de 172 dias com temperatura média de $15,7^{\circ} \mathrm{C}$ (CRSA, 2006), enquanto, na região de Rauscedo, norte daquele país, a duração do ciclo é de 163 dias com temperatura média de $18,8^{\circ} \mathrm{C}$ (Vivai Cooperativi Rauscedo, 2006). Assim, na região norte do Paraná a uva 'Malvasia Bianca' apresenta em média um ciclo 46 dias mais curto que as regiões produtoras citadas.

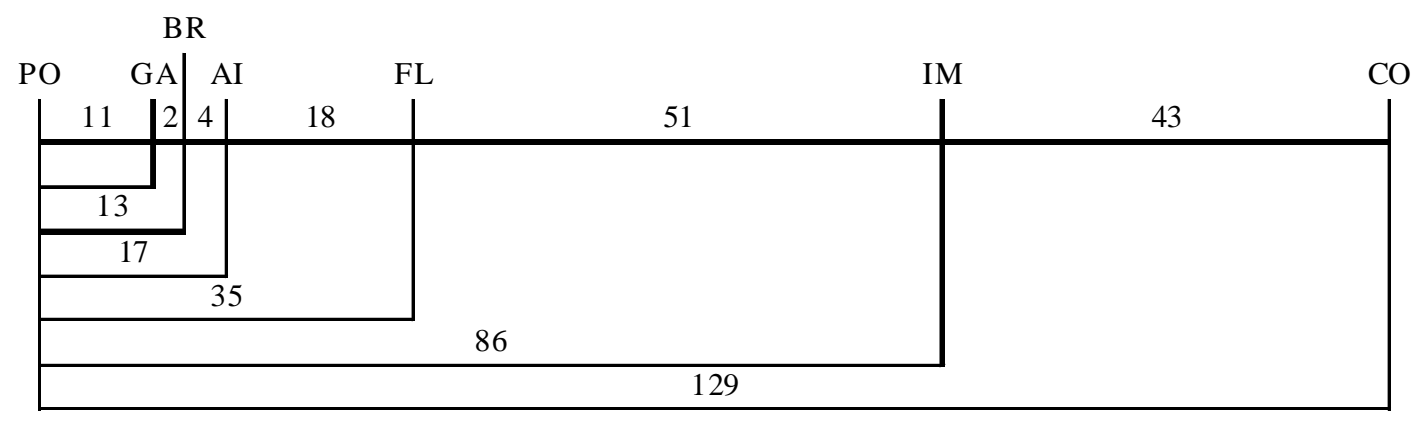

(A)

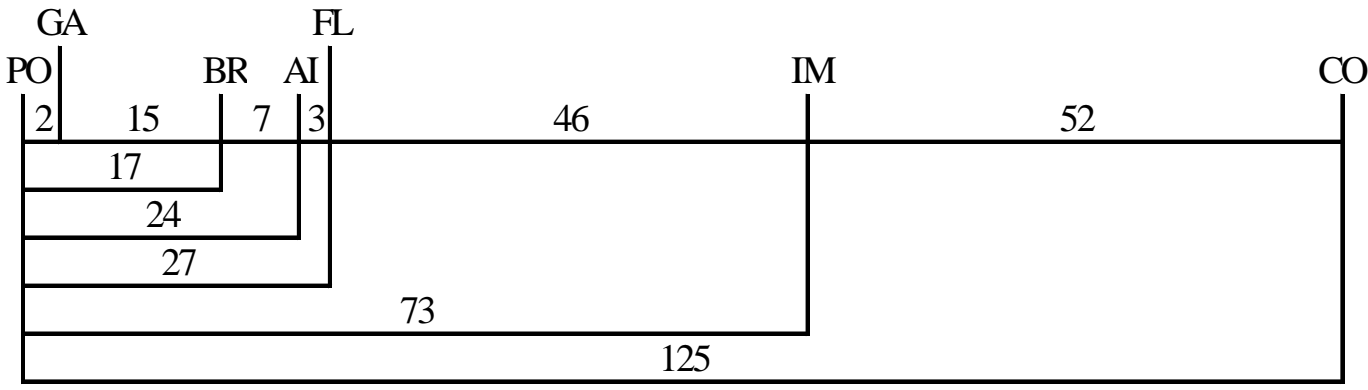

(B)

Figura 1. Duração em dias dos estágios fenológicos da videira 'Malvasia Bianca' em Maringá, PR. (A): safra 2004/2005 e (B): safra 2005/2006. (PO): Poda; (GA): Gema-algodão; (BR): Brotação; (AI): Aparecimento da Inflorescência; (FL): Florescimento; (CO): Colheita. 
A variação observada do ciclo da videira em estudo de uma safra para outra, que resultou em uma média de 127 dias, ocorreu, pois, de um ano para outro em regiões subtropicais podem acontecer variações climáticas, principalmente em relação à temperatura e chuva. Como observado nos Anexos 1 e 2 , na fase vegetativa que compreende da poda ao florescimento na primeira safra obteve 35 dias e na segunda 27 , isto se deve por temperaturas médias mais altas e precipitação mais baixa neste período na segunda safra. Na fase reprodutiva que compreende do florescimento à colheita obteve-se 94 e 98 dias na primeira e segunda safra respectivamente, observado também nos Anexos 1 e 2 que neste período temperaturas médias mais altas e maior precipitação na primeira safra acarreta-se um número menor de dias.

Observa-se que na fase de maturação que corresponde do início da maturação à colheita foi obtido 43 e 52 dias na primeira safra e segunda respectivamente, isto se deve por ter ocorrido temperaturas médias mais baixas na primeira safra porém com maior precipitação e umidade relativa menor (mas que não prejudica-se o acumulo de SST) fazendo com que nesta fase o acumulo de sólidos solúveis totais atingi-se sua maior expressão obtendo a colheita (Anexos 1 e 2).

Em condições de temperatura alta e clima seco há um acumulo maior de açúcares nas bagas durante a maturação, ocasionando a colheita um pouco mais cedo, ao passo que em condições de temperatura alta, clima úmido e chuvas constantes, há uma diluição dos açúcares nas bagas, retardando assim a colheita (BLOUIN \& GUIMBERTEAU, 2004).

Temperaturas médias mais elevadas favorecem o crescimento vegetativo acelerado da videira, ocasionando a diminuição de seu ciclo (TONIETTO \& MANDELLI, 2003), ou seja, isto é uma vantagem porque no norte do Paraná há a possibilidade, dependendo do ciclo da videira de serem produzidas duas safras anuais. Realizando-se a poda seca de frutificação da 'Malvasia Bianca' no final de julho, a colheita seria possível no início de dezembro. Em seguida, realizando-se a poda verde de frutificação no fim de dezembro com posterior estímulo da brotação por meio da aplicação de cianamida hidrogenada, seria possível a obtenção da segunda safra anual no início de maio. Isto seria uma ótima vantagem, pois o setor produtivo (campo e indústria) estaria operando praticamente o ano todo, onde a oferta de vinhos jovens ao mercado seria mais ampla.

O conhecimento da duração do ciclo da videira resulta em outras vantagens, podendo-se, por exemplo, programar datas de poda, quebra de dormência, aplicação de defensivos, colheita e também otimizar o emprego da mão-de-obra nas diversas fases do ciclo reduzindo os tratos fitossanitários, resultando em economia de insumos (MURAKAMI, 2002). Além disso, em função do histórico do regime de chuvas de uma região subtropical, poderia ser melhor programada a poda de frutificação e quebra de dormência para que a colheita não coincida com o maior período de chuvas, uma vez que neste período é importante que não haja excesso de umidade nos cachos, evitando-se assim a ocorrência de podridões fúngicas que prejudicam o processo fermentativo.

\section{Características químicas}

Em relação à evolução do pH do mosto da uva 'Malvasia Bianca', os dados melhor se ajustaram à regressão cúbica $\left(\mathrm{R}^{2}=0,97\right)$ em duas safras estudadas (Figura 2). 


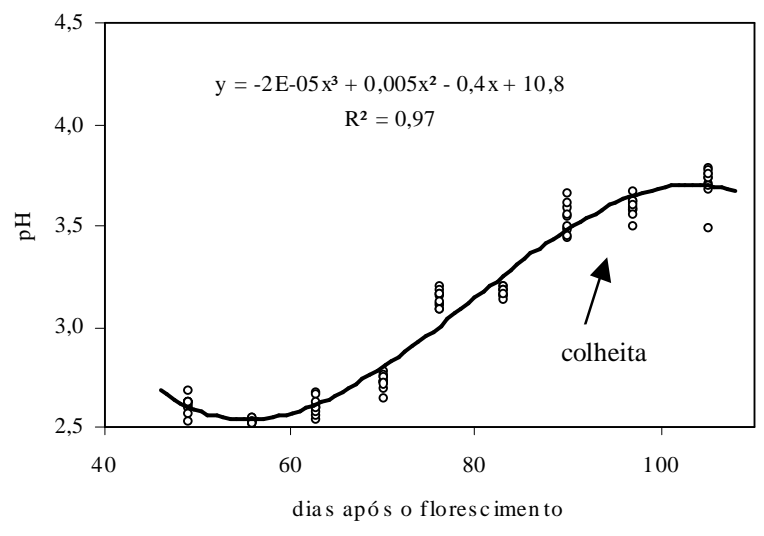

(A)

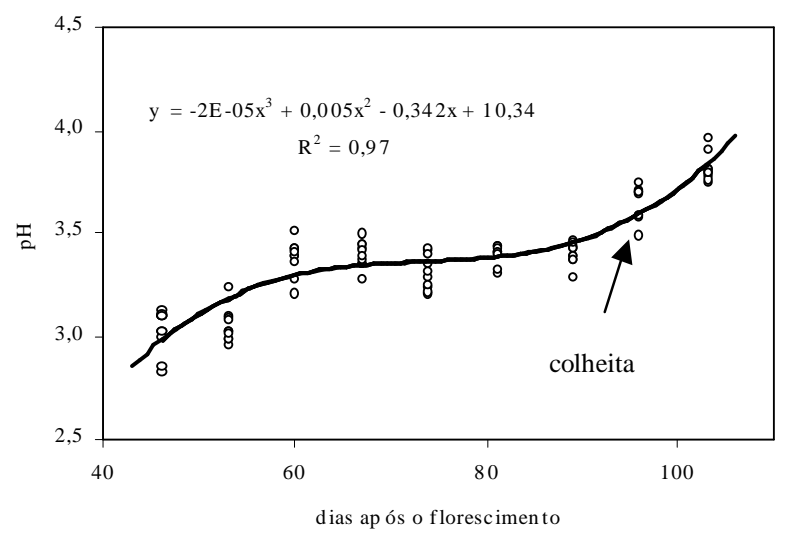

(B)

Figura 2. Evolução do $\mathrm{pH}$ do mosto durante a maturação da uva 'Malvasia Bianca' em Maringá, PR. (A): safra 2004/ 2005 e (B): safra 2005/2006.
Observa-se que o $\mathrm{pH}$ do mosto foi crescente no período avaliado, atingindo na colheita 3,6 nas duas safras (Tabela 1). Entre os fatores determinantes do cresci destacam-se a salificação dos ácidos orgânicos, o processo respiratório e a diluição devido ao aumento do tamanho da baga (RIZZON \& MIELE, 2001).

$\mathrm{O} \mathrm{pH}$ do mosto observado neste trabalho é semelhante ao observado por outros autores que avaliaram uvas finas brancas para vinificação. $\mathrm{Na}$ província de Bari Itália, determinou-se que a uva 'Malvasia Bianca' atinge na colheita $\mathrm{pH}=3,2$ (CRSA, 2006), enquanto na Serra Gaúcha, o pH da uva 'Moscato Branco' segundo Guandalin et al. (2005) atinge $\mathrm{pH}=3,2$. Nas regiões de Salinas Valley e Nappa Valley, Califórnia, Wolpert et al. (1994) e Bettiga (2003) constataram que a uva 'Chardonnay' é colhida em média com $\mathrm{pH}$ do mosto próximo a 3,5 e 3,7 respectivamente.

Sendo que o pH do mosto de uvas para elaboração de vinhos não deve ultrapassar de 3,3 , pois em condições de pH baixo, os mostos estão mais protegidos da ação das enzimas oxidativas durante a fase pré-fermentativa. Ao contrário, vinhos com $\mathrm{pH}$ elevado são mais suscetíveis às alterações oxidativas e biológicas, uma vez que o teor de dióxido de enxofre livre é proporcionalmente menor (RIZZON \& MIELE, 1998).

Tabela 1. Características químicas das bagas da videira 'Malvasia Bianca' (Vitis vinifera L.) no momento da colheita em Maringá, PR.

\begin{tabular}{cccc}
\hline Características químicas & $2004 / 2005$ & Safra & Média \\
\hline $\mathrm{pH}$ & $3,6 \pm 0,04$ & $3,6 \pm 0,08$ & 3,6 \\
$\mathrm{SST}^{\mathrm{a} /}$ & $21,3 \pm 0,6$ & $21,2 \pm 0,62$ & 21,2 \\
$\left({ }^{\circ} \mathrm{Brix}\right)$ & & & 0,6 \\
$\mathrm{AT}^{\mathrm{b} /}$ & $0,6 \pm 0,04$ & $0,6 \pm 0,34$ & \\
$(\%$ de ácido tartárico $)$ & & & 36,0 \\
\hline
\end{tabular}

a/: Sólidos solúveis totais.

${ }^{\mathrm{b} /}$ : Acidez titulável. 
Desta forma, em situações onde o pH do mosto é superior a 3,3, conforme observado para a 'Malvasia Bianca' neste trabalho, faz-se necessária a adição de ácidos orgânicos (ácido tartárico) para corrigir o seu pH antes do início da fermentação.

Quanto à evolução do teor de SST do mosto durante a fase de maturação, os dados se ajustaram melhor à regressão cúbica $\left(\mathrm{R}^{2}=0,97\right)$ nos dois anos de estudo (Figura 3). Observa-se que a evolução do teor de SST foi progressiva desde o início da maturação, atingindo na colheita 21,3 e 21,2 ${ }^{\circ}$ Brix no primeiro e no segundo ano, respectivamente (Tabela 1 ), o que resulta em média $21,2^{\circ}$ Brix.

Na província de Bari, Itália e no Rio Grande do Sul verificou-se que a uva 'Malvasia Bianca' é colhida em média com teor de SST igual a 19 e18 ${ }^{\circ}$ Brix, respectivamente(CRSA, 2006; GIOVANNINI, 1999), enquanto em Farroupilha-RS, Guandalin et al. (2005) descrevem que a uva 'Moscato Branco', cujas características são parecidas com a 'Malvasia Bianca', é colhida com teor de SST igual a $17,9^{\circ}$ Brix.

Em função das Figuras 1 e 3, o início da maturação da uva 'Malvasia Bianca' cultivada no norte do Paraná ocorre em média aos 48,5 dias após o florescimento, onde a partir deste período há um ganho acelerado de SST nas bagas. Isto se deve ao acúmulo de açúcar por meio da fotossíntese das folhas que migram pelo floema e chegam em forma de sacarose nas bagas. Posteriormente, a sacarose é hidrolizada e transformada em glicose e frutose que são os açúcares predominantes nas bagas, por duas invertases, uma na membrana plasmática e outra no vacúolo das células (BLOUIN \& GUIMBERTEAU, 2004).

Os valores médios do teor de SST da uva 'Malvasia Bianca' cultivada em Maringá indicam o potencial de cultivo desta videira na região, uma vez que esta característica é muito importante para a elaboração de vinhos brancos finos de qualidade, porque, todo o álcool formado deve ser via fermentação dos açúcares pelas leveduras, sem adição exógena
(GUERRA \& ZANUS, 2003). Segundo a legislação brasileira, o vinho de mesa deve ter em torno de 10 a $13^{\circ} \mathrm{GL}$ de álcool, sendo que para obtenção de $1^{\circ} \mathrm{GL}$ de álcool na fermentação são necessárias cerca de 18 $\mathrm{g} / \mathrm{L}$ de açúcar na uva. Desta forma, com o teor médio de SST observado neste trabalho $\left(21,2^{\circ}\right.$ Brix $)$, pode-se elaborar vinhos finos brancos de qualidade que respeitam a legislação brasileira e principalmente sem adição exógena de açúcares.

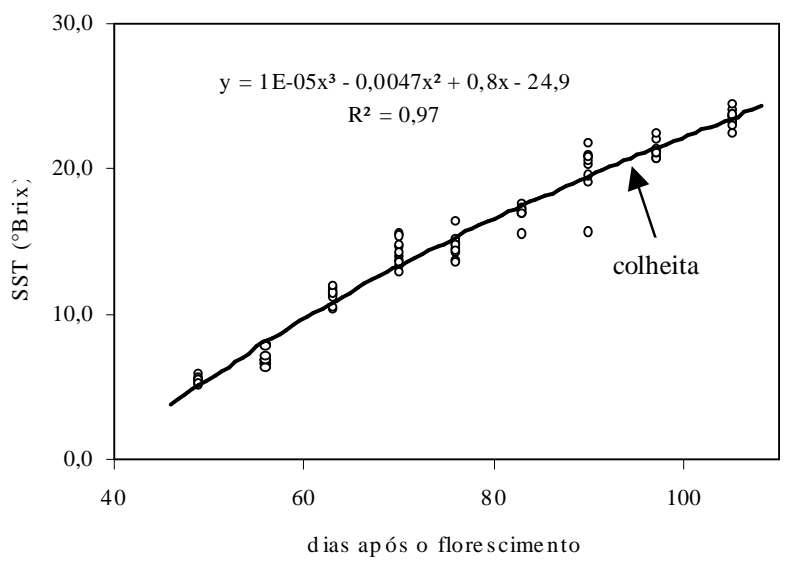

(A)

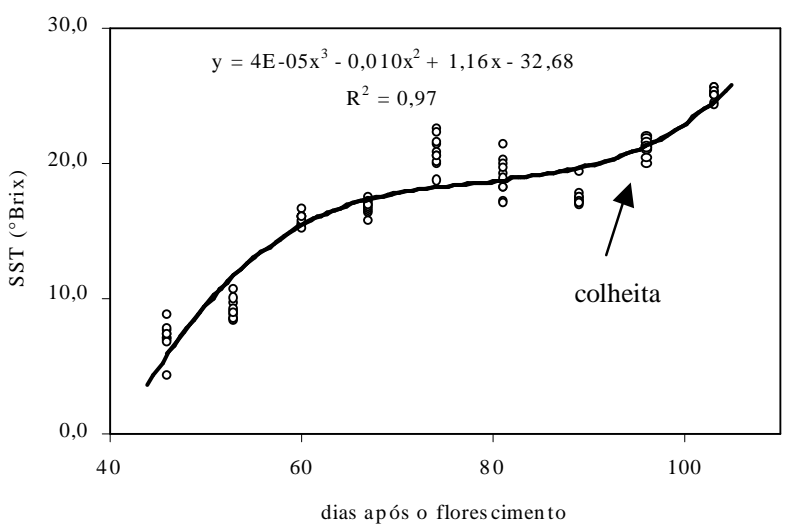

(B)

Figura 3. Evolução do teor de sólidos solúveis totais (SST) do mosto durante a maturação da uva 'Malvasia Bianca' em Maringá, PR. (A): safra 2004/2005 e (B): safra 2005/2006. 
A evolução da AT do mosto durante a fase de maturação foi negativa, ou seja, decrescente e inversa em relação à evolução do teor de SST. Nos dois anos de avaliação, os dados se ajustaram melhor à regressão cúbica $\left(\mathrm{R}^{2}=0,97\right)$ (Figura 4). Constatou-se que o mosto desta uva durante a colheita apresenta $0,6 \%$ de ácido tartárico nas duas safras avaliadas (Tabela 1).

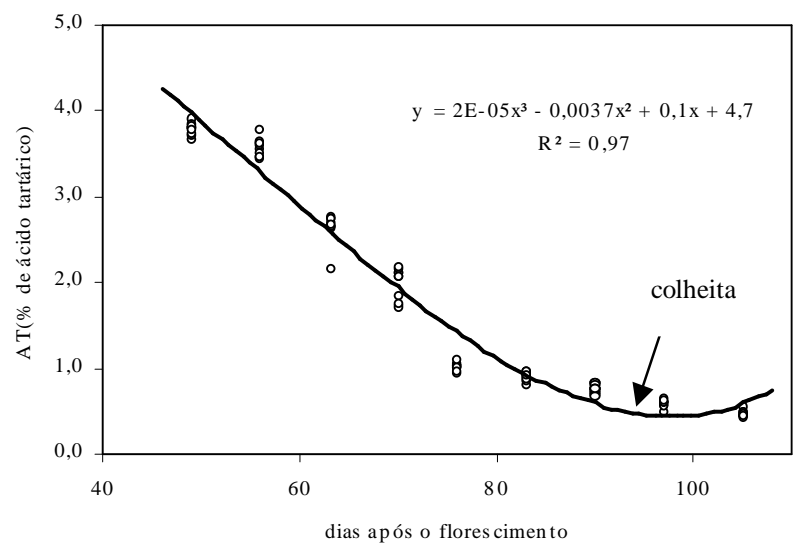

(A)

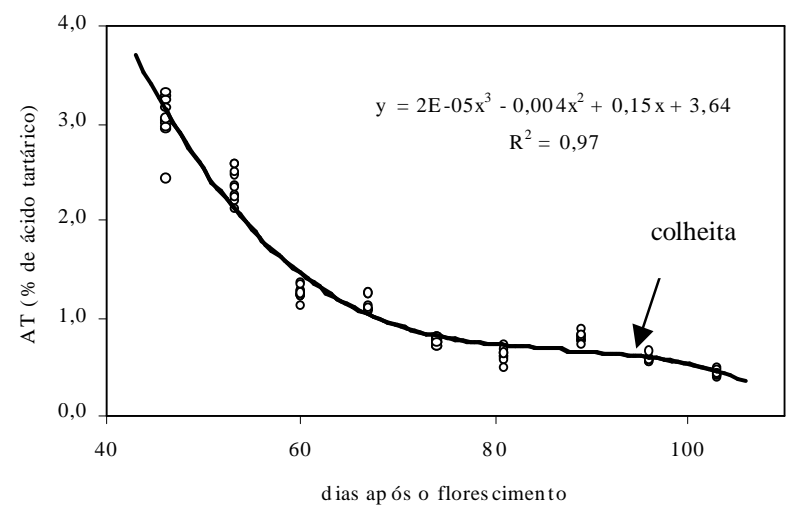

(B)

Figura 4. Evolução da acidez titulável (\% de ácido tartárico) do mosto durante a maturação da uva 'Malvasia Bianca' em Maringá, PR. (A): safra 2004/2005 e (B): safra 2005/2006.

Na província de Bari, Itália e no Rio Grande do Sul verificou-se que a uva 'Malvasia Bianca' é colhida em média com AT igual a 0,6 e $0,8 \%$ de ácido tartárico, respectivamente (CRSA, 2006; GIOVANNINI, 1999).

Nas regiões de Salinas Valley e Nappa Valley, Califórnia, Wolpert et al. (1994) e Bettiga (2005) constataram que a uva 'Chardonnay' é colhida em média com AT do mosto próximo a 0,65 e $0,72 \%$ de ácido tartárico, respectivamente.

As médias obtidas neste trabalho são semelhantes às observadas pelos outros autores citados, o que indica que a uva 'Malvasia Bianca' cultivada na região de Maringá contém acidez adequada para a elaboração de vinhos brancos finos de qualidade.

Em função das Figuras 1 e 4, verifica-se que a partir do início da maturação das bagas ocorreu uma sensível redução da acidez do mosto. Isto se deve a diversos fatores, entre eles: diluição dos ácidos orgânicos por aumento do volume da baga; ativação da quebra de ácidos orgânicos e inibição de sínteses e transformação dos ácidos orgânicos em açúcar (MULLINS et al., 1992). Dentre os ácidos orgânicos existentes nas bagas se destacam o tartárico e o málico com 95\% sua totalidade (BLOUIN \& GUIMBERTEAU, 2004).

Em relação à evolução do índice de maturação do mosto (SST/AT), os dados se ajustaram à regressão cúbica $\left(R^{2}=0,99\right)$ nas duas safras estudadas (Figura 5), sendo que durante a colheita o índice foi de 35,7 na primeira safra e 36,3 na segunda, respectivamente (Tabela 1). Os valores desta relação para o mosto da uva 'Malvasia Bianca', em média 36 , estão próximos ao observado na região de Bari, Itália $(31,6)$ (CRSA, 2006), mas em comparação ao encontrado no Rio Grande do Sul $(21,7)$, este índice encontra-se maior (GIOVANNINI, 1999). Estas diferenças entre as regiões podem variar de acordo com a forma de cultivo e as condições climáticas, o que reflete diferenças no acúmulo de SST e redução de AT no mosto (SANTOS, 2005).

Ressalta-se que a utilização da relação SST/AT como índice de maturação deve ser feita com cuidado, pois nem sempre um aumento de açúcar corresponde à uma diminuição da acidez titulável e não é indicada para comparar mostos de diferentes cultivares (RIZZON \& MIELE, 2003). Este índice serve, portanto como referência de uma safra considerada ótima sob o ponto de vista enológico (BLOUIN \& GUIMBERTEAU, 2004). 


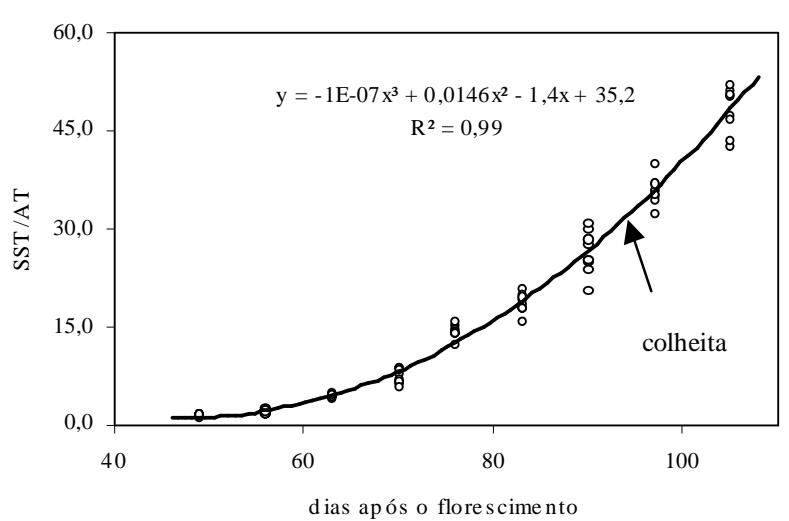

(A)

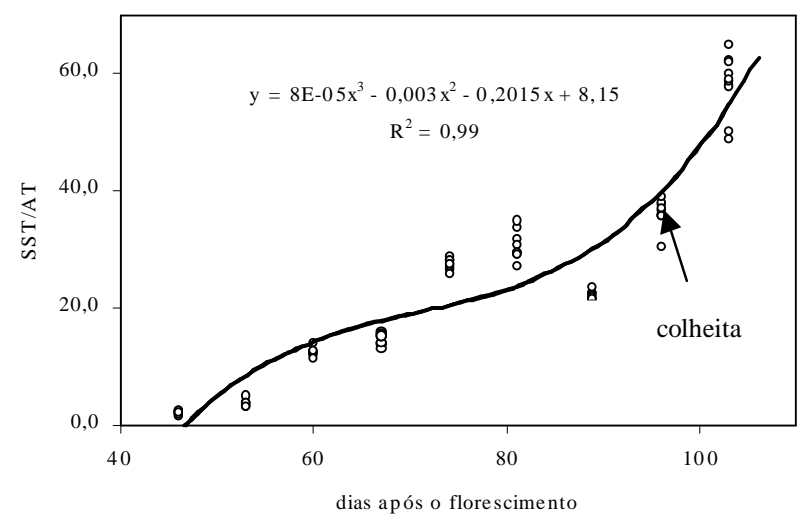

(B)

Figura 5. Evolução da relação entre o teor de sólidos solúveis totais (SST) e a acidez titulável (AT) do mosto durante a maturação da uva 'Malvasia Bianca' em Maringá, PR. (A): safra 2004/2005 e (B): safra 2005/2006.

\section{Características produtivas}

Observa-se que as médias de diâmetro e massa das bagas da uva 'Malvasia Bianca' nas safras 2004/ 2005 e 2005/2006 foram de 16 e $15,1 \mathrm{~mm}$ e 2,4 e $2,1 \mathrm{~g}$, respectivamente (Tabela 2).

$\mathrm{Na}$ região de Bari, sul da Itália, estas características são semelhantes, com massa média das bagas de 2,5g (CRSA, 2006). Detoni et al. (2005) descrevem que a uva 'Moscato Embrapa', que apresenta características semelhantes à 'Malvasia Bianca', quando cultivada em Maringá, PR, apresenta bagas de $15,5 \mathrm{~mm}$ e $2,5 \mathrm{~g}$, resultados estes próximos aos observados neste trabalho. As médias do número de cachos por planta, massa dos cachos, produção por planta e produtividade nas duas safras avaliadas foram de 75,9 e 48,2; 0,4 e 0,26kg; 27,5 e $12,5 \mathrm{~kg} /$ planta; e 45,8 e 20,8t/ha, respectivamente, sendo as médias das safras iguais a $62 ; 0,33 \mathrm{~kg} ; 20 \mathrm{~kg} /$ planta e 33,3t/ha, respectivamente (Tabela 2).

Os resultados indicam que esta variedade cultivada sobre o porta-enxerto IAC 766 é extremamente produtiva na região de Maringá principalmente se comparada com a região da Serra Gaúcha, onde segundo Giovannini (1999), apresenta média ao redor de 18t/ha (Giovannini, 1999),

Em geral, constata-se uma relação inversa entre a produtividade do vinhedo e a qualidade da uva e, conseqüentemente, do vinho, ou seja, normalmente os vinhos de qualidade são elaborados com uvas provenientes de vinhedos com produtividades intermediárias, por apresentarem melhores características químicas de qualidade para elaboração de vinhos (Winkler, 2002). Por exemplo, em Maringá, a videira 'Malvasia Bianca' expressou todo seu vigor e produtividade na sua primeira safra, ainda mais em um porta-enxerto muito vigoroso como o IAC 766. Assim, a videira em sua segunda safra tinha menos reservas, resultando em uma queda brusca de todas as características produtiva avaliadas.

Contudo, observou-se uma produtividade muito boa na segunda safra $(20,8 \mathrm{t} / \mathrm{ha})$, principalmente se comparada ao Rio Grande do Sul, cuja produtividade média é de 18 t/ha, o que demonstra a excelente adaptação da uva 'Malvasia Bianca' para as condições locais.

Desta forma, faz-se necessário limitar a produção a cada ano desta videira através do raleio dos cachos até um nível adequado, não permitindo que a mesma atinja níveis muitos elevados em uma safra e que consequentemente, não haja queda de produtividade no próximo ciclo produtivo. 
Tabela 2. Características físicas da produção da videira 'Malvasia Bianca' (Vitis vinifera L.) em Maringá, PR.

\begin{tabular}{|c|c|c|c|}
\hline \multirow[t]{2}{*}{ Características da produção } & \multicolumn{2}{|c|}{ Safra } & \multirow{2}{*}{ Média } \\
\hline & $2004 / 2005$ & $2005 / 2006$ & \\
\hline $\begin{array}{l}\text { diâmetro médio das bagas } \\
(\mathrm{mm})\end{array}$ & $16 \pm 0,7$ & $15,1 \pm 0,7$ & 15,5 \\
\hline $\begin{array}{c}\text { massa média das bagas } \\
(\mathrm{g})\end{array}$ & $2,4 \pm 0,2$ & $2,1 \pm 0,1$ & 2,2 \\
\hline $\begin{array}{l}\text { número médio de cachos } \\
\text { por planta }\end{array}$ & $75,9 \pm 11,8$ & $48,2 \pm 20,7$ & 62,0 \\
\hline $\begin{array}{l}\text { massa média dos cachos } \\
\qquad(\mathrm{kg})\end{array}$ & $0,4 \pm 0,05$ & $0,3 \pm 0,08$ & 0,3 \\
\hline $\begin{array}{l}\text { produção média por planta } \\
\qquad(\mathrm{kg} / \text { planta })\end{array}$ & 27,5 & 12,5 & 20,0 \\
\hline $\begin{array}{c}\text { produtividade média }{ }^{\mathrm{b} /} \\
(\mathrm{t} / \mathrm{ha})\end{array}$ & 45,8 & 20,8 & 33,3 \\
\hline
\end{tabular}

a: Estimativa em função do número médio de cachos por planta e da massa média dos cachos.

${ }^{\mathrm{b}}$ : Estimativa em função da produção média por planta e do número de plantas por hectare.

\section{Conclusões}

Pelas avaliações realizadas em duas safras consecutivas da videira 'Malvasia Bianca' cultivada no norte do Paraná, pode-se concluir que esta videira apresenta excelente adaptação às condições locais, fornecendo matéria prima adequada para a elaboração de vinhos brancos aromáticos. Dentre as principais características desta videira, destacam-se:

- A duração do seu ciclo (poda à colheita) é em média 127 dias.

- Os teores médios de $\mathrm{pH}, \mathrm{SST}, \mathrm{AT}$ e o SST/AT do mosto são de 3,6; 21,2 ${ }^{\circ}$ Brix; 0,6\% de ácido tartárico e 36 , respectivamente.

- Suas médias de produção por planta e produtividade são de $20 \mathrm{~kg} /$ planta e 33,3 t/ha, respectivamente.

\section{Agradecimentos}

À Vinícola Intervin ${ }^{\circledR}$ por fornecer a área para a realização deste trabalho.

Ao CNPq, pelo apoio financeiro.

À Universidade Estadual de Londrina.

À Universidade Estadual de Maringá, pelo fornecimento dos dados climáticos.

\section{Referências Bibliográficas}

BAILLOD, M.; BAGGIOLINI, M. Lês stades repères de la vigne. Revue Suisse Viticulture Horticulture, Croft, v.25, n.1, p.7-9, 1993.

BAGGIOLINI, M. Lês stades repères dans lê developpement anual de la vigne. Revue Romande dágriculture de viticulture et dárboriculture, v.8, p.4-5, 1952.

BETTIGA, L. J. Comparison of seven chardonnay clonal selections in the Salinas Valley. American Journal of Enology and Viticulture, v.53, p.203-206, 2003.

BLOUIN, J.; GUIMBERTEAU, G. Maduracion y madurez de la uva. Madrid: Ediciones Mundi-Prensa, 2004. 


\section{Anexos}

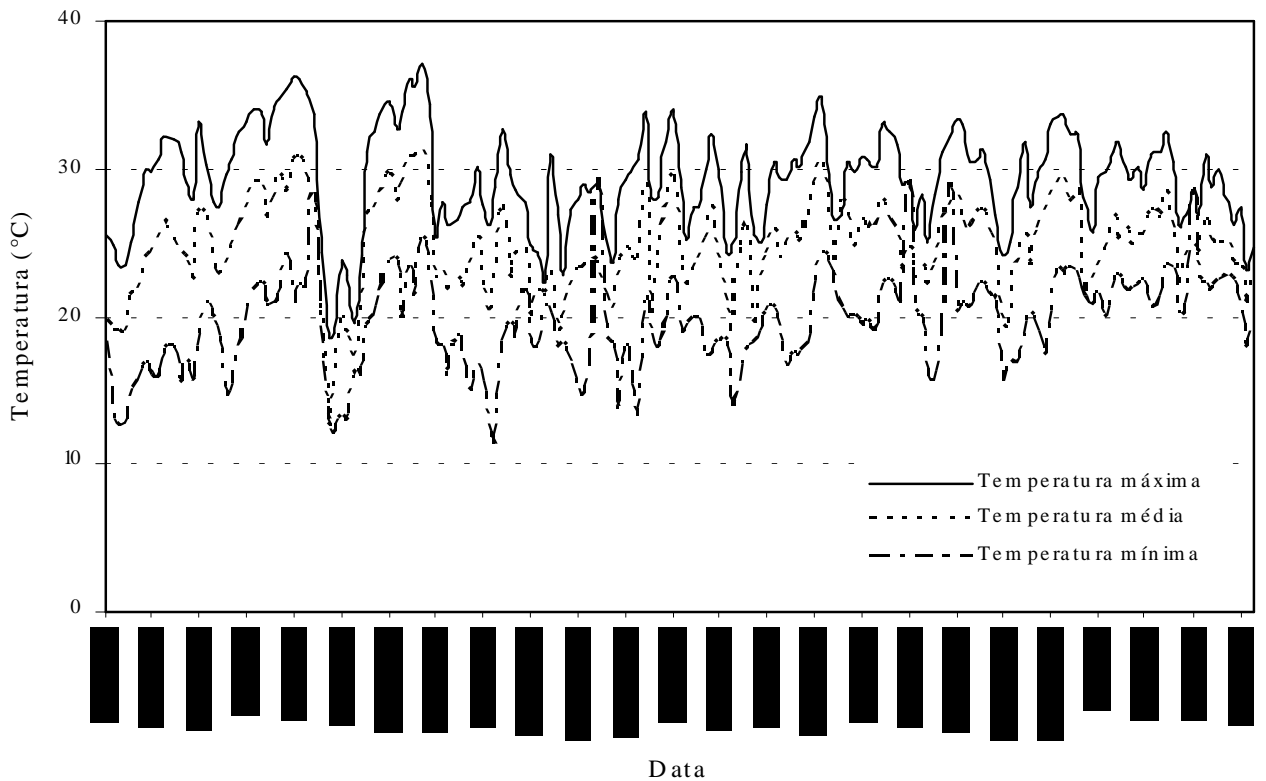

(A)

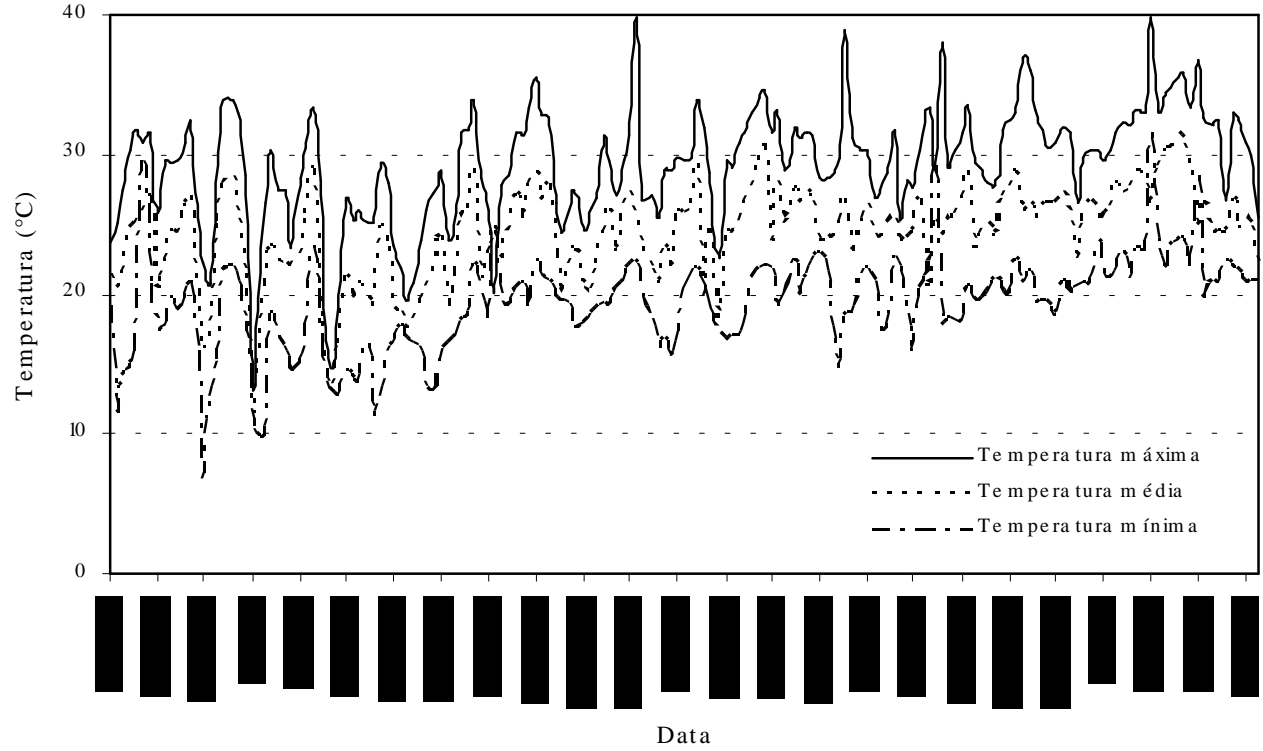

(B)

Anexo 1. Temperaturas máximas, médias e mínimas diárias $\left({ }^{\circ} \mathrm{C}\right)$ na região de Maringá, $\mathrm{PR}$, no período de 11 de agosto de 2004 a 28 de janeiro de 2005 (A) e 11 de agosto de 2005 a 28 de janeiro de 2006 (B). Fonte: Universidade Estadual de Maringá. 


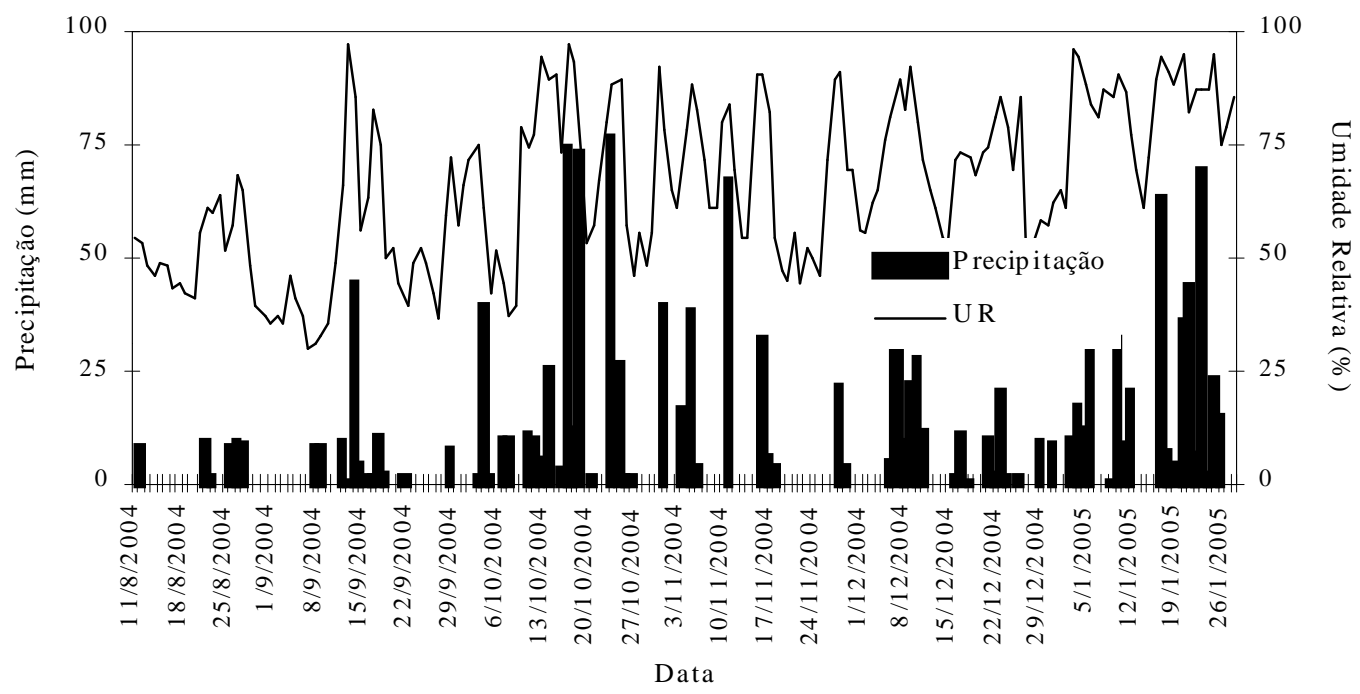

(A)

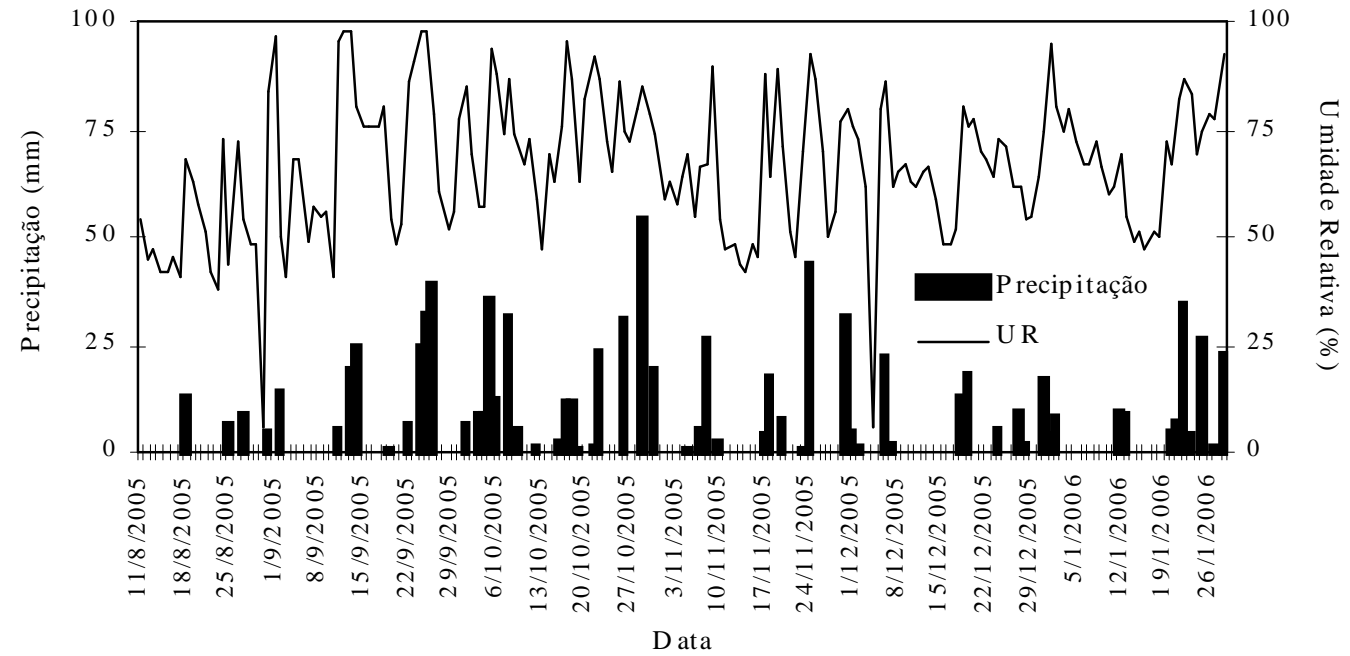

(B)

Anexo 2. Umidade relativa média (\%) e precipitação diária $(\mathrm{mm})$ na região de Maringá, $\mathrm{PR}$, no período de 11 de agosto de 2004 a 28 de janeiro de 2005 (A) e 11 de agosto de 2005 a 28 de janeiro de 2006 (B). Fonte: Universidade Estadual de Maringá. 
BOLIANI, J. Avaliação fenológica de videira Vitis vinifera L. cv. Itália e cv. Rubi na região oeste do Estado de São Paulo.1994. Tese (Doutorado em Agronomia) Faculdade de Ciências Agrárias e Veterinárias, Universidade Estadual Paulista, Jaboticabal.

BORROZINO, E. Média dos dados climáticos da região Norte do Paraná. Londrina: IAPAR, 2004.

CENTRO DI RICERCA E SPERIMENTAZIONE IN AGRICOLTURA "BASILE CARAMIA". Vitigno MALVASIA BIANCA DI CANDIA clone UBA 26/E. Disponível em: <http://www.crsa.it/ricerca-esperimentazione/documenti/vitigno-malvasia-bianca-dlcandia-clone-uba-26-e> Acesso em 19.set.2006.

CORRÊA, S. Anuário brasileiro de uva e do vinho. Santa Cruz do SuL: Gazeta Santa Cruz, 2005.

DETONI, A .M.; CLEMENTE, E. Características quimicas da uva Moscato Embrapa cultivada na Região Oeste do Paraná. In: CONGRESSO LATINO-AMERICANO DE VITICULTURA E ENOLOGIA, 10., 2005, Bento Gonçalves. Anais... Bento Gonçalves, RS: Embrapa Uva e Vinho, 2005. p.334.

- Avaliação física da uva moscato Embrapa cultivada na Região Oeste do Paraná. . In: CONGRESSO LATINO-AMERICANO DE VITICULTURA E ENOLOGIA, 10., 2005, Bento Gonçalves. Anais... Bento Gonçalves, RS: Embrapa Uva e Vinho, 2005. p. 335.

GIOVANINI, E. Produção de uvas para vinho, suco e mesa. Porto Alegre: Renascença, 1999.

GUANDALIN, D. P. et al. Características da uva Moscato Branco de Farroupilha, RS. In: CONGRESSO LATINOAMERICANODE VITICULTURAEENOLOGIA, 10., 2005, Bento Gonçalves. Anais... Bento Gonçalves, RS: Embrapa Uva e Vinho, 2005. p. 323.

GUERREIRO, V. M. Avaliação fenológica da videira (Vitis labrusca L. $x$ Vitis vinifera L.) cultivar Niagara Rosada na região de Selvíria-MS. 1997. Dissertação (Mestrado em Agronomia). Faculdade de Engenharia de Ilha Solteira. Universidade Estadual Paulista, SP.

INSTITUTO ADOLFO LUTZ. Normas analíticas do Instituto Adolfo Lutz: métodos químicos e físicos para análise dos alimentos. 3 ed. São Paulo: Instituto Adolfo Lutz, 1985. v.1, 371 p.

JIMENEZ, J. J., RUIZ, V. S. Phenological development of Vitis vinifera L. in Castilla - La Mancha (Spain). Study of 21 cultivars (10 red and 11 white cultivars). Acta Horticulturae, n.388, p.105-110, 1995.

MELLO, L. M. R. Anuário brasileiro de uva e do vinho. Santa Cruz do Sul: Gazeta Santa Cruz, 2004.
MULLINS, F.; BOUQUET, A.; WILLIAMS, L. E. Biology of the grapevine. Cambridge: University Press, 1992.

MURAKAMI, R. K. et al. Caracterização fenológica da videira cv. Itália (Vitis vinífera $\mathrm{L}$.) sob diferentes épocas na região norte do estado do Rio de Janeiro. Revista Brasileira de Fruticultura, Jaboticabal, v.24, n.3, p.615$617,2002$.

RIZZON, L.A.; ZANUZ, M.C.; MIELE, A. Evolução da acidez durante a vinificação de uvas tintas de três regiões viticolas do Rio Grande do Sul. Ciências e Tecnologia de Alimentos, Campinas, v.18, n.2, p.179-183, 1998.

RIZZON, L.A.; MIELE, A. Avaliação da cv. Cabernet Franc para elaboração de vinho tinto. Ciências e Tecnologia de Alimentos, Campinas, v.21, no.2, p.249-255. 2001

. Avaliação da cv. Merlot para elaboração de vinho tinto. Ciência e Tecnologia de Alimentos, Campinas, v.23, p.156-161, 2003.

. Avaliação da cv. Tannat para elaboração de vinho tinto. Ciência e Tecnologia de Alimentos, Campinas, v.24, n.2, p.223-229, 2004.

ROBERTO, S. R. et al. Antecipação da maturação da Uva 'Rubi' produzida for a de estação no noroeste do Paraná. Revista Brasileira de Fruticultura, Jaboticabal, v. 24, n. 3, p.780-782, 2002a.

Efeito da época do anelamento do tronco na antecipação da maturação da uva "Rubi". Acta Scientiarum, v.24, n.5, p.1307-1312, 2002b.

SANTOS, H. P. et al Cultivo protegido de Cabernet Sauvignon: caracterídticas físico-quimicas da uva e do vinho. In: CONGRESSOLATINO-AMERICANODE VITICULTURAE ENOLOGIA, 10., 2005, Bento Gonçalves. Anais... Bento Gonçalves, RS: Embrapa Uva e Vinho, 2005. p. 276.

SOUSA, J. S. I. Uvas para o Brasil. 2.ed. Piracicaba: FEALQ, 1996.

TONIETTO, A.; MANDELLI, F. Uvas viníferas para processamento em região de clima temperado. Disponível em: <http://www.cnpuv.embrapa.br/publica/ sprod/UvasViniferasRegioesClimaTemperado/clima.htm>. Acesso em 01.nov.2006.

VIVAICOOPERATIVI RAUSCEDO. Catalogo. Disponível em : <http://www.vivairauscedo.com/> Acesso 19.set.2006.

WOLPERT, J. A.; KASIMATIS, A. N.; WEBER, E. Field Performance of Six Chardonnay Clones in the Napa Valley. American Journal of Enology and Viticulture, v.45, p.393400, 1994.

WINKLER, A. J. et al. General viticulture. Califórnia: University of California Press, Berkley, 2002. 
